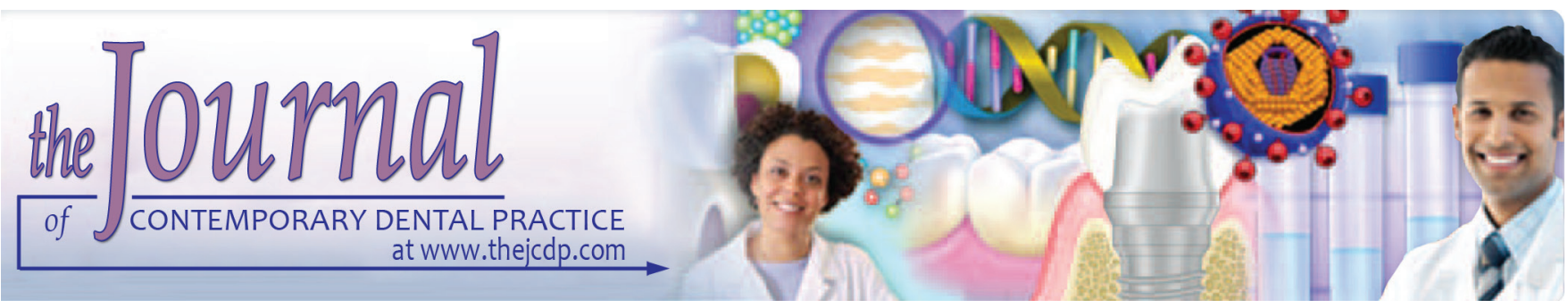

\title{
Action of Chlorhexidine, Zingiber officinale, and Calcium Hydroxide on Candida albicans, Enterococcus faecalis, Escherichia coli, and Endotoxin in the Root Canals
}

\author{
${ }^{1}$ Marcia C Valera, ${ }^{2}$ Sarah AC Oliveira, ${ }^{3}$ Lilian E Maekawa, ${ }^{4}$ Flávia GR Cardoso, ${ }^{5}$ Adriana Chung \\ ${ }^{6}$ Stephanie FP Silva, ${ }^{7}$ Cláudio AT Carvalho
}

\begin{abstract}
Aim: The purpose of this in vitro study was to evaluate the antimicrobial activity of $2 \%$ chlorhexidine gel ( $\mathrm{CHX}$ ) as auxiliary chemical substance and intracanal medications on Candida albicans, Enterococcus faecalis, Escherichia coli, and their endotoxins in the root canals.
\end{abstract}

Materials and methods: The study was conducted on 48 single-rooted human teeth divided into four groups $(n=12)$, according to intracanal medications used: (1) Calcium hydroxide + apyrogenic saline solution $\left(\mathrm{Ca}(\mathrm{OH})_{2}+\mathrm{SS}\right)$, (2) $20 \%$ ginger glycolic extract (GEN), (3) calcium hydroxide $+20 \%$ ginger glycolic extract $\left(\mathrm{Ca}(\mathrm{OH})_{2}+\mathrm{GEN}\right)$, (4) apyrogenic SS (control). Collections were made from the root canal content before preparation (baseline-S1), immediately after instrumentation (S2), 7 days after instrumentation (S3), after 14 days the action of intracanal medication (S4), and 7 days after removal of the intracanal medication (S5). The antimicrobial activity and endotoxin content were analyzed for all collections. The results were statistically analyzed by the Kruskal-Wallis and Dunn tests at a significance level of $5 \%$.

Results: After instrumentation with $\mathrm{CHX}$, there was complete elimination of $E$. coli and $C$. albicans, except for $E$. faecalis, which was significantly reduced and then completely eliminated after intracanal medication. There was significant reduction of endotoxin after instrumentation. Comparison of collection after instrumentation and intracanal medication revealed reduction

1-3,5-7 Department of Restorative Dentistry, Institute of Science and Technology, UNESP_Univ Estadual Paulista, São José dos Campos, São Paulo, Brazil

${ }^{4}$ Division of Endodontics, Department of Odontology, University of Taubaté, Taubaté, São Paulo, Brazil

Corresponding Author: Marcia C Valera, Department of Restorative Dentistry, Institute of Science and Technology UNESP-Univ Estadual Paulista, São josé dos Campos, São Paulo, Brazil, CEP 12245-000, Phone: (55) 1239479400 e-mail:marcia@fosjc.unesp.br of endotoxins in all groups; this reduction was greater in group $\mathrm{Ca}(\mathrm{OH})_{2}$ followed by the group GEN.

Conclusion: It was concluded that the instrumentation using $\mathrm{CHX}$ and intracanal medication used were able to eliminate the microorganisms from the root canal; the endotoxins were reduced, yet not completely eliminated.

Clinical significance: This study is important and relevant for searching alternatives during endodontic therapy, since it aims to study the effect of Zingiber officinale on microorganisms and endotoxins present in root canals.

Keywords: Chlorhexidine, Endotoxins, Intracanal medications, Microorganisms, Zingiber officinale.

How to cite this article: Valera MC, Oliveira SAC, Maekawa LE, Cardoso FGR, Chung A, Silva SFP, Carvalho CAT. Action of Chlorhexidine, Zingiber officinale, and Calcium Hydroxide on Candida albicans, Enterococcus faecalis, Escherichia coli, and Endotoxin in the Root Canals. J Contemp Dent Pract 2016; 17(2):114-118.

Source of support: This work was supported by the Brazilian agencies FAPESP (2007/58848-4).

Conflict of interest: The authors report no conflicts of interest.

\section{INTRODUCTION}

Root canal cleaning and disinfection are fundamental steps for the success of endodontic treatment, and cleaning is performed simultaneously with instrumentation. ${ }^{1}$ This, in turn, consists of root canal instrumentation associated with auxiliary chemicals, which are essential for the elimination of microorganisms, mainly responsible for the appearance of pulp and periapical lesions. Hundreds of species of microorganisms have been isolated and identified in infected root canals, including yeasts. ${ }^{2}$ Enterococcus faecalis has been isolated in root canals, especially in cases of persistent infections. ${ }^{3-5}$ Infected root canals also exhibit large quantities of Gram-negative 
bacteria, ${ }^{6}$ which have endotoxins on the cell wall that are lipopolysaccharide complexes (LPSs) with powerful cytotoxic action. This LPS released during cell duplication or depth represents an important virulence factor of these bacteria. Thus, for the success of endodontic therapy, its neutralization is important to assure the treatment success. $^{7}$

Chlorhexidine has been used as auxiliary chemical due to its wide antimicrobial spectrum, ${ }^{8}$ substantivity, ${ }^{8-10}$ and relative lack of cytotoxicity. ${ }^{11}$ However, even after instrumentation, bacteria and endotoxins may remain in the dentinal tubules, and intracanal medication is used to complement the antimicrobial action of instrumentation. $^{12}$

Calcium hydroxide is the most used intracanal medication, either pure or associated with other drugs. ${ }^{9,12-14}$ However, in the last years, there has been increasing interest in the utilization of natural substances in different biological areas as an alternative treatment method, due to the possibility of fewer toxic effects to the organism and less aggression to the environment.

Due to its healing, anti-inflammatory, and antimicrobial action, Zingiber officinale has been used pure or associated with other substances, in cooking and medical areas as dentistry, though there are few related studies. Grégio et $\mathrm{al}^{15}$ evaluated the glycolic and alcoholic extracts of Z. officinale on Streptococcus mutans, Staphylococcus aureus, Escherichia coli, and Candida albicans and observed that both glycolic and alcoholic extracts presented relevant antimicrobial and antifungal activity for dentistry, possibly contributing to the treatment of diseases caused by these microorganisms present in the oral cavity.

The properties of Z. officinale suggest that it may have clinical applicability, as root canal irrigant or even as intracanal medication. Thus, this in vitro study evaluated the action of root canal preparation using $2 \%$ chlorhexidine gel, followed by intracanal medication with calcium hydroxide, glycolic Z. officinale extract or their association, on microorganisms and endotoxins.

\section{MATERIALS AND METHODS}

\section{Preparation and Contamination of Specimens}

The study was conducted on 48 recently extracted single-rooted human teeth, which were cleaned after extraction and had their crowns sectioned with carborundum disk, standardizing the length of specimens in $16 \pm 0.5 \mathrm{~mm}$, and immersed in saline solution (SS) until utilization. Initial root canal instrumentation was performed throughout their extent, from the anatomical diameter up to Kerr file n.30 (Dentsply Ind Com Ltda.,
Petrópolis, RJ, Brazil). The root canals were irrigated with SS (Laboratório Sanobiol, Pouso Alegre, MG, Brazil) at each change of instrument. After instrumentation, the root canals were irrigated with $17 \%$ ethylenediaminetetraacetic acid (EDTA; Inodon, Porto Alegre, RS, Brazil) for 3 minutes, followed by final irrigation with $10 \mathrm{ml}$ of SS. The external apical region of the roots was externally impermeabilized with epoxy adhesive (Brascola, São Paulo, Brazil), except for the cervical opening. The 48 roots were randomly divided in cell culture plates with 24 wells (TPP, Switzerland) and fixated with chemically cured acrylic resin (Dencor Artigos Odontológicos Clássico, São Paulo, Brazil). The plates were covered, wrapped, and sterilized with the materials employed by Cobalt-60 gamma irradiation (20 KGy for 6 hours). The microorganisms C. albicans (ATCC 18804), E. faecalis (ATCC 29212), and E. coli (ATCC 25922) were used. In sterile environment (laminar flow chamber), the root canals were contaminated with $10 \mu$ l of suspension of E. coli and $10 \mu \mathrm{l}$ of brain-heart infusion (BHI) broth (Himedia Laboratories, Mumbai, India). Apyrogenic cotton pellets soaked in BHI broth were placed in the root canal openings and the specimens were kept in an oven at $37 \pm 1^{\circ} \mathrm{C}$, in relative humidity, for 7 days. After this period, $5 \mu$ l of suspension of C. albicans, $5 \mu \mathrm{l}$ of suspension of E. faecalis, and $10 \mu \mathrm{l}$ of BHI broth were added to the root canals. A new apyrogenic cotton pellet soaked in BHI broth was placed in the root canal openings, and the specimens were kept in an oven at $37 \pm 1^{\circ} \mathrm{C}$, in relative humidity, for 21 days, with addition of BHI broth to the root canals every 2 days. ${ }^{9}$

\section{Experimental Groups}

After 28 days of contamination, the root canal content was collected to confirm the contamination (baseline, S1). For collection, the root canals were filled with sterile apyrogenic SS and $100 \mu \mathrm{l}$ was collected from the root canal with $1 \mathrm{ml}$ apyrogenic syringes. This content was placed in eppendorfs containing $900 \mu$ l of sterile and apyrogenic SS. Serial dilutions and plating were performed in duplicate in agar Sabouraud dextrose with chloramphenicol for C. albicans, agar Enterococcosel for E. faecalis, and agar MacConkey for E. coli. After root canal preparation with $2 \%$ chlorhexidine gel, a new collection was obtained from the root canal (Sample 2-S2), similar to the confirmation collection. After collection, the root canals were filled with sterile and apyrogenic SS and sealed with apyrogenic cotton pellet and, after 7 days, the third collection (Sample 3-S3) was obtained, similar to the previous collections. Thereafter, the root canals were filled with the intracanal medications: (1) Calcium hydroxide + apyrogenic SS $\left(\mathrm{Ca}(\mathrm{OH})_{2}+\mathrm{SS}\right),(2) 20 \%$ ginger glycolic extract (GEN), 
(3) Calcium hydroxide $+20 \%$ ginger glycolic extract $\left(\mathrm{Ca}(\mathrm{OH})_{2}+\mathrm{GEN}\right),(4)$ apyrogenic SS (control).

Following this, serial dilutions were made for later plating and analysis of endotoxin. Before placement of intracanal medication, EDTA was applied for 3 minutes followed by root canal irrigation with $10 \mathrm{ml}$ of apyrogenic SS. The root canals were kept in an oven at $37^{\circ} \mathrm{C}$ for 14 days in relative humidity. Thereafter, the fourth collection of the root canal content was obtained (Sample 4-S4). The root canals were filled with apyrogenic SS and once again placed in an oven. After 7 days, the fifth collection was obtained (Sample 5-S5), as previously described. Serial dilutions of root canal content samples were made, plated in duplicate in three selective culture media for each microorganism, and the plates were kept in an oven at $37^{\circ} \mathrm{C}$ for 24 hours, to determine the colonyforming units $/ \mathrm{ml}$.

The results were statistically analyzed by the KruskalWallis and Dunn tests, at a significance level of 5\%. To verify the neutralization of endotoxin, the chromogenic test of Limulus amebocyte lysate (quantitative analysis) was made using the kinetic reader QCL. The results of this test were statistically analyzed by the Kruskal-Wallis and Dunn tests, at a significance level of 5\%.

\section{RESULTS}

There was elimination of microorganisms after instrumentation (S2) except for E. faecalis. Seven days after preparation (S3), all microorganisms were eliminated, as well as after intracanal medication (collection, S4, and S5), for all groups (Tables 1 and 2). The endotoxin values are expressed in Tables 3 and 4 .

Table 1: Percentages of reduction of CFU/ml obtained in the second (S2) and third (S3) collections in relation to baseline (S1)

\begin{tabular}{llllll}
\hline & Microorganisms & $n$ & Mean & Median & HG \\
\hline S1 & Candida albicans & 48 & 100 & 100 & $\mathrm{~A}$ \\
$\mathrm{X}$ & Enterococcus faecalis & 48 & 99.99 & 100 & $\mathrm{~A}$ \\
S2 & Escherichia coli & 48 & 100 & 100 & $\mathrm{~A}$ \\
S1 & Candida albicans & 48 & 100 & 100 & $\mathrm{~A}$ \\
$\mathrm{X}$ & Enterococcus faecalis & 48 & 100 & 100 & $\mathrm{~A}$ \\
S3 & Escherichia coli & 48 & 100 & 100 & $\mathrm{~A}$ \\
\hline
\end{tabular}

HG: Homogeneous groups; Different letters indicate statistically significant differences $(p<0.05)$; CFU: Colony-forming units

Table 2: Percentages of reduction of CFU/ml obtained in the fourth (S4) and fifth (S5) collections in relation to baseline (S1)

\begin{tabular}{|c|c|c|c|c|c|c|c|c|c|c|c|c|}
\hline \multirow[b]{3}{*}{ Groups } & \multicolumn{6}{|c|}{$S 1 \times S 4$} & \multicolumn{6}{|c|}{$S 1 \times S 5$} \\
\hline & \multicolumn{2}{|c|}{$\begin{array}{l}\text { Candida } \\
\text { albicans }\end{array}$} & \multicolumn{2}{|c|}{$\begin{array}{l}\text { Enterococcus } \\
\text { faecalis }\end{array}$} & \multicolumn{2}{|c|}{ Escherichia coli } & \multicolumn{2}{|c|}{ Candida albicans } & \multicolumn{2}{|c|}{$\begin{array}{l}\text { Enterococcus } \\
\text { faecalis }\end{array}$} & \multicolumn{2}{|c|}{ Escherichia coll } \\
\hline & Median & $H G$ & Median & $H G$ & Median & $H G$ & Median & $H G$ & Median & $H G$ & Median & $H G$ \\
\hline $\mathrm{Ca}(\mathrm{OH})_{2}+\mathrm{SS}$ & 100 & $A$ & 100 & $A$ & 100 & $A$ & 100 & $A$ & 100 & $A$ & 100 & $A$ \\
\hline GEN & 100 & A & 100 & $A$ & 100 & $A$ & 100 & A & 100 & $A$ & 100 & $A$ \\
\hline $\mathrm{Ca}(\mathrm{OH})_{2}+\mathrm{GEN}$ & 100 & $A$ & 100 & A & 100 & $A$ & 100 & A & 100 & $A$ & 100 & $A$ \\
\hline SS (Control) & 100 & A & 100 & $A$ & 100 & $A$ & 100 & $A$ & 100 & $A$ & 100 & $A$ \\
\hline
\end{tabular}

HG: Homogeneous groups; Different letters indicate statistically significant differences $(p<0.05)$; SS: Saline solution; GEN: Ginger glycolic extract; CFU: Colony-forming units; $n=12$ for each group

Table 3: Percentages of reduction in the quantity of endotoxin (EU/ml) obtained in the second (S2) and third (S3) collections in relation to baseline (S1)

\begin{tabular}{lllll}
\hline Reductions & $n$ & Mean & Standard deviation & Median \\
\hline S1 S2 & 48 & 92.49 & 25.64 & 98.59 \\
S1 S3 & 48 & 81.63 & 66.23 & 99.11 \\
\hline
\end{tabular}

EU: Endotoxin units

Table 4: Percentages of reduction in the quantity of endotoxin (EU/ml) obtained in the fourth (S4) and fifth (S5) collections in relation to baseline (S1) and homogeneous groups

\begin{tabular}{|c|c|c|c|c|c|c|}
\hline \multirow[b]{2}{*}{ Groups } & \multicolumn{3}{|c|}{$S 1 \times S 4$} & \multicolumn{3}{|c|}{$S 1 \times S 5$} \\
\hline & Mean & Median & Homogeneous groups* & Mean & Median & Homogeneous groups \\
\hline $\mathrm{Ca}(\mathrm{OH})_{2}+\mathrm{SS}$ & 99.62 & 99.76 & $A$ & 99.33 & 99.65 & $A$ \\
\hline GEN & 91.5 & 98.26 & A & 95.72 & 98.56 & $A$ \\
\hline $\mathrm{Ca}(\mathrm{OH})_{2}+\mathrm{GEN}$ & 75.5 & 98.3 & A & 73.5 & 97.9 & A \\
\hline SS (Control) & 55.7 & 98.4 & A & 85.95 & 96.86 & A \\
\hline
\end{tabular}

Different letters indicate statistically significant differences $(p<0.05)$; EU: Endotoxin units; SS: Saline solution; GEN: Ginger glycolic extract; $n=12$ for each group 


\section{DISCUSSION}

Microorganisms and their by-products present in root canals with necrotic pulp invade the periapical tissues, promoting inflammatory reaction and consequent tissue destruction. ${ }^{16,17}$ These microorganisms, present in the root canals, are diverse according to the duration of the infection process, and primary infections may present different microbiota compared with secondary infections. Secondary infections often exhibit E. faecalis ${ }^{18}$ and C. albicans. ${ }^{19}$ Especially, E. faecalis is able to remain in root canals with failure of endodontic therapy because of their ability to invade the dentinal tubules and adhere to collagen in the presence of human serum, besides being able to survive in environments with few nutrients. ${ }^{4,20}$ Yeasts were also observed in $7 \%$ of root canals with persistent periapical infections, $80 \%$ of these yeasts being C. albicans. ${ }^{19}$

Escherichia coli is a microorganism widely investigated in the last years. According to Siqueira et al, ${ }^{21}$ E. coli is present in $3.7 \%$ of acute periapical abscesses, when evaluated by the checkerboard deoxyribonucleic acid (DNA)-DNA hybridization. Moreover, its endotoxin presents the basic structure of the lipid component, which represents the active center responsible for the toxicity of LPS. Selection of E. coli in this study was based on several investigations in the literature that used its endotoxin to analyze the induction of periapical lesions. ${ }^{7,22}$

The microbiological analysis of this study revealed that, immediately after root canal preparation using $2 \%$ chlorhexidine gel, there was elimination of microorganisms except for the species E. faecalis, which was still resistant. After 7 days there was no growth of microorganisms, evidencing their complete elimination. The chlorhexidine exhibited effective antimicrobial action, as reported in previous studies. The action of chlorhexidine occurs because its molecule is positively charged and the cell wall of microorganisms seems to be negatively charged, leading to electrostatic interaction and altering the osmotic balance of the cell. The increased permeability of the cell wall allows the chlorhexidine molecule to penetrate into the bacteria. When chlorhexidine is used in high concentrations, there is precipitation of cytoplasm, with consequent death of the microorganism. ${ }^{23}$

The intracanal medications maintained the antimicrobial action obtained by root canal preparation, acting on microorganisms that might have remained in the dentinal tubules and other areas of the root canal system. This study employed calcium hydroxide as intracanal medication considering its widespread use in endodontics because of its antimicrobial properties, ${ }^{24,25}$ ability to induce mineralization, ${ }^{26}$ and especially the effective action on LPS, $7,22,27$ either pure or associated with other drugs. ${ }^{9,14,23}$
Due to studies using phytotherapic drugs, this study employed Z. officinale extract as intracanal medication, associated or not with calcium hydroxide. Many studies ${ }^{28-30}$ demonstrate that the main pharmacological actions of Z. officinale and its isolated compounds include immunomodulatory, antitumorigenic, anti-inflammatory, antiapoptotic, antihyperglycemic, and antiemetic properties. Also, Ali et al ${ }^{30}$ demonstrate that ginger is a powerful antioxidant and considered a safe phytotherapic drug, with few and nonsignificant side effects. Grégio et $\mathrm{al}^{15}$ demonstrated that ginger (Z. officinale) is rich in volatile oils, Gingerol and Shogaol, which present analgesic, healing, and anti-inflammatory properties and antimicrobial activity. According to Lantz et $\mathrm{al}^{31}$ and Jung et $\mathrm{al}^{32}$ the 6-Gingerol is able to inhibit the production of prostaglandins E2, interleukin-1t, cyclooxygenase-2 and nitric oxide synthesis stimulated by LPS, with possible utilization in autoimmune diseases and chronic inflammations. In this study, it was observed that ginger was effective in the reduction of microorganisms and endotoxins, yet it was unable to completely eliminate them. However, it should be highlighted that, without statistically significant difference, the association of ginger and calcium hydroxide revealed promising outcomes, with complete elimination of endotoxins in some specimens.

Therefore, considering the importance to eliminate microorganisms and their by-products from the root canal system for endodontic treatment success and the constant search for drugs that may eliminate these microorganisms, investigations on natural drugs are highly relevant, which may allow the use of a chemical substance able to act on microorganisms and their by-products with less adverse effects to the human body and environment. The present results demonstrated that the chemicals were able to eliminate the microorganisms, promoting significant reduction of endotoxins, yet without their complete elimination. Ginger, a phytotherapic drug used in this study, may be an option to be investigated in in vivo studies, especially associated with calcium hydroxide, which demonstrates satisfactory outcomes.

\section{CONCLUSION}

According to the present methodology and results, the following could be concluded: (1) biomechanical preparation using $1 \%$ chlorhexidine gel and the medications used were able to eliminate microorganisms from the root canal and significantly reduce the endotoxins; (2) the medications reduced the endotoxins, yet did not completely eliminate the LPS.

\section{REFERENCES}

1. MarchesanMA,ArudaMP,SilvaSousa YTC,SaquyPC,PecoraJD, Sousa Neto MD. Morphometrical analysis of cleaning capacity 
using nickel-titanium rotary instrumentation associated with irrigating solutions in mesio-distal flattened root canals. J Appl Oral Sci 2003 Mar;11(1):55-59.

2. Najzar-Fleger D, Filipovic D, Prpic G, Kobler D. Candida in root canal in accordance with oral ecology. Int Endod J 1992;25:40.

3. Sundqvist G, Figdor D, Persson S, Sjogren U. Microbiologic analysis of teeth failed endodontic treatment and the outcome of conservative retreatment. Oral Surg Oral Med Oral Pathol Oral Radiol Endod 1998 Jan;85(1):86-93.

4. Love RM. Enterococcus faecalis - a mechanism for its role in endodontic failure. Int Endod J 2001 Jul;34(5):399-405.

5. Sunde PT, Olsen Y, Debelian GJ, Tronstad L. Microbiota of periapical lesions refractory to endodontic therapy. J Endod 2002 Apr;28(4):304-310.

6. Siqueira JF Jr, Rôças IN. Polymerase chain reaction-based analysis of microorganisms associated with failed endodontic treatment. Oral Surg Oral Med Oral Pathol Oral Radiol Endod 2004 Jan;97(1):85-94.

7. de Oliveira LD, Carvalho CAT, Valera MC, Koga-Ito CY, Jorge AOC. Diffusion ability of endotoxin through dentinal tubules. Braz Oral Res 2005 Jan-Mar;19(1):5-10.

8. Vahdaty A, Pitt Ford TR, Wilson RF. Efficacy of chlorhexidine in disinfecting dentinal tubules in vitro. Endod Dent Traumatol 1993 Dec;9(6):243-248.

9. Menezes MM, Valera MC, Koga-Ito CY, Camargo CHR, Mancini MNG. In vitro evaluation of the effectiveness of irrigants and intracanal medicaments on microorganisms within root canals. Int Endod J 2004 May;37(5):311-319.

10. Sena NT, Gomes BPFA, Vianna ME, Berber VB, Zaia AA, Ferraz CC, Souza-Filho FJ. In vitro antimicrobial activity of sodium hypochlorite and chlorhexidine against selected single-species biofilms. Int Endod J 2006 Nov;39(11):878-885.

11. Gomes BP, Vianna ME, Zaia AA, Almeida JF, Souza-Filho FJ, Ferraz CC. Chlorhexidine in endodontics. Braz Dent J 2013;24(2):89-102.

12. Maekawa LE, Valera MC, Oliveira LD, Carvalho CA, KogaIto $\mathrm{CY}$, Jorge $\mathrm{AO}$. In vitro evalution of the actions of irrigating solutions associated with intracanal medications on Escherichia coli and its endotoxin in root canals. J Appl Oral Sci 2011 Apr;19(2):106-112.

13. Valera MC, Rosa JA, Maekawa LE, Olivira LD, Carvalho CAT, Koga-ito CY, Jorge AO. Action of propolis and medications against Escherichia coli and endotoxin in root canals. Oral Surg, Oral Med, Oral Pathol, Oral Radiol Endod 2010 Oct;110(4):e70-e74.

14. Sakamoto M, Siqueira Junior JF, Rôças IN, Benno Y. Bacterial reduction and persistence after endodontic treatment procedures. Oral Microbiol Immunol 2007 Feb;22(1):19-23.

15. Grégio AMT, Fortes ESM, Rosa EAR, Simeoni RB, Rosa RT. Antimicrobial action of Zingiber officinale front of the oral microbiota. Rev Est Biol 2006;28:61-66.

16. Nair PNR. Pathogenesis of apical periodontitis and the causes of endodontic failures. Crit Rev Oral Biol Med 2004 Nov 1;15(6):348-381.

17. Siqueira JF Jr, Rôças IN, Alves FRF, Silva MG. Bacteria in the apical root canal of teeth with primary apical periodontitis.
Oral Surg, Oral Med, Oral Pathol, Oral Radiol Endod 2009 May;107(5):721-726.

18. Stuart $\mathrm{CH}$, Schwartz AS, Beeson TJ, Owatz CB. Enterococcus faecalis: its role in root canal treatment failure and current concepts in retreatment. J Endod 2006 Feb;32(2):93-98.

19. Waltimo TMT, Sirén EK, Torkko HLK, Olsen L, Haapasalo MPP. Fungi in therapy-resistant apical periodontitis. Int Endod J 1997 Mar;30(2):96-101.

20. Gomes BPFA, Pinheiro ET, Gadê-Neto CR, Sousa ELR, Ferraz CCR, Zaia AA, Teixeira FB, Souza-Filho FJ. Microbiological examination of infected dental root canals. Oral Microbiol Immunol 2004 Apr;19(2):71-76.

21. Siqueira JF Jr, Rôças IN, Souto R, Uzeda M, Colombo AP. Microbiological eveluation of acute periradicular abscesses by DNA-DNA hybridization. Oral Surg Oral Med Oral Pathol Oral Radiol Endod 2001 Oct;92(4):451-457.

22. Nelson Filho P, Leonardo MR, Silva LAB, Assed S. Radiographic evaluation of the effect of endotoxin (LPS) plus calcium hydroxide on apical and periapical tissues of dogs. J Endod 2002 Oct;28(10):694-696.

23. Gomes BPFA, Souza SFC, Ferraz CCR, Teixeira FB, Zaia AA, Valdrighi L, Souza-Filho FJ. Effectiveness of $\%$ chlorhexidine gel and calcium hydroxide against Enterococcus faecalis in bovine root dentine in vitro. Int Endod J 2003 Apr;36(4):267-275.

24. Sjogren U, Figdord D, Spangberg L, Sundqvist G. The antimicrobial effect of calcium hydroxide as a short-term intracanal dressing. Int Endod J 1991 May;24(3):119-125.

25. Siqueira JF Jr, Lopes HP. Mechanisms of antimicrobial activity of calcium hydroxide: a critical review. Int Endod J 1999 Sep;32(5):361-369.

26. Leonardo MR, Silveira FF, Silva LAB, Tanomaru Filho M, Utrilla LS. Calcium hydroxide root canal dressing. Histopathological evaluation of periapical repair at different time periods. Braz Dent J 2002;13(1):17-22.

27. Leonardo MR, Silva LAB, Assed S, Nelson-Filho P. Importance of bacterial endotoxin (LPS) in endodontics. J Appl Oral Sci 2004 Jun;12(2):93-98.

28. Pereira ACP, Grégio AMT, Barbosa APM, Marques FR, Lima AAS, Ribas MO. Study of the effect of ginger on the healing of ulcers in the oral mucosa of rats. Pesqui Odontol Bras 2003;17:76.

29. Chrubasik S, Pittler MH, Roufogalis BD. Zingiberis rhizoma: a comprehensive review on the ginger effect and efficacy profiles. Phytomedicine 2005 Sep;12(9):684-701.

30. Ali BH, Blunden G, Tanira MO, Nemmar A. Some phytochemical, pharmacological and toxicological properties of ginger (Zingiber officinale Roscoe): a review of recent research. Food Chem Toxicol 2008 Feb;46(2):409-420.

31. Lantz RC, Chen GJ, Sarihan M, Sólyom AM, Jolad SD, Timmermann BN. The effect of extracts from ginger rhizome on inflammatory mediator production. Phytomedicine 2007 Feb;14(2-3):123-128.

32. Jung HW, Yoon CH, Park KM, Han HS, Park YK. Hexane fraction of zingiberis rhizoma crudus extract inhibits the production of nitric oxide and proinflammatory cytokines in LPS-stimulated BV2 microglial cells via the NF-KappaB pathway. Food Chem Toxicol 2009 Jun;47(6):1190-1197. 